\title{
EUREXIT? High time to consider the merits of European collaboration in child and adolescent psychiatry
}

\author{
Johannes Hebebrand ${ }^{1} \cdot$ Bruno Falissard $^{2}$ - Pieter J. Hoekstra ${ }^{3} \cdot$ Michael Kaess $^{4,5} \cdot$ Maria Melchior $^{6} \cdot$ Nadia Micali $^{7}$. \\ Carmen Moreno $^{8} \cdot$ Nanda Rommelse $^{9} \cdot$ Veit Roessner $^{10} \cdot$ Giulia Signorini $^{11}$
}

Published online: 25 May 2019

○) Springer-Verlag GmbH Germany, part of Springer Nature 2019

As editors of European Child and Adolescent Psychiatry (ECAP), the official journal of the European Society of Child and Adolescent Psychiatry (ESCAP), we have been witnessing the aftermath of the British referendum in 2016, which ended with a slight majority voting for Brexit. We are also keenly aware of the growing nationalistic and populist movements across Europe and beyond. Thus, we eagerly await the results of the upcoming European elections.

As editors and researchers, we are all largely removed from politics in our respective countries. Just like everyone else we have opinions, feelings and visions related to the future of Europe. However, within our professional livesand in particular as editors of a European journal-we feel an obligation to make ourselves heard to promote European collaboration for the advancement of research and its dissemination in child and adolescent psychiatry, which forms the basis for improvement of our clinical work helping children with mental disorders and their families.

European science is already threatened by the recent political developments. A recent Nature editorial published

Johannes Hebebrand

johannes.hebebrand@uni-due.de

1 Department of Child and Adolescent Psychiatry, Psychosomatics and Psychotherapy, University Hospital Essen, Essen, Germany

2 Université Paris-Sud, Orsay, France

3 Department of Child and Adolescent Psychiatry, University of Groningen, University Medical Center Groningen, Groningen, Netherlands

4 University Hospital of Child and Adolescent Psychiatry and Psychotherapy, University of Bern, Bern, Switzerland

5 Department of Child and Adolescent Psychiatry, University Hospital Heidelberg, Heidelberg, Germany

6 Department of Social Epidemiology, INSERM, Sorbonne Université, Institut Pierre Louis d'Epidémiologie et de Santé Publique IPLESP, 75012 Paris, France in April 2019 commented on how Brexit has already irreparably damaged science in the United Kingdom (UK) [13]. Vice versa, science in continental Europe, too, suffers substantially from a loosening of the tight link to the excellent research community in the UK and its many individual scientists themselves. Overall, potential reductions of the amount of and the access to EU research funding are to be deplored. The creation of barriers to immigration of overseas researchers negatively impacts collaborations and poses a risk to the solid worldwide reputation of European research.

Our field has lots to lose. In many countries, the scientific basis of child and adolescent psychiatry is still rather limited. Accordingly, we require collaborations at the European level to obtain funding, recruit sufficient sample sizes, and gain access to different technologies among other advantages brought on by cross-country co-operations. Our Journal ECAP figures prominently with respect to publications of articles based on European collaborations or dwelling on trans-European clinical issues [1-12, 14, 15, 17-19].

7 Département Universitaire de Psychiatrie, Université de Genève, 1211 Genève 4, Switzerland

8 Department of Child and Adolescent Psychiatry, Institute of Psychiatry and Mental Health, Hospital General Universitario Gregorio Marañón, School of Medicine, Universidad Complutense, IiSGM, CIBERSAM, Madrid, Spain

9 Radboudumc Department of Psychiatry and Karakter Child and Adolescent Psychiatry, Nijmegen, The Netherlands

10 Department of Child and Adolescent Psychiatry, TU Dresden, Dresden, Germany

11 IRCCS Istituto Centro San Giovanni di Dio Fatebenefratelli, Brescia, Italy 
Eurexit (we use this term to describe a cessation of efforts to enable European collaborations) would entail that we stay glued to our well-established national academic and clinical routines. We have all made our careers within our national scenarios, which accordingly have worked well for us. We know our ways around in the respective health care systems. We do, however, realize that the career opportunities are not equal throughout Europe (and across the globe) and we also perceive a thinning out of individuals willing to embark on an academic career within our field even in European countries that have a solid infrastructure for child and adolescent psychiatry.

Only few of us have worked in more than one country entailing that a thorough bi- or even multinational assessment of both the clinical and research environments is not part of most of our scopes. Indeed, in a recent editorial, we probed possible explanations for discrepant rates of particular diagnoses between child and adolescent psychiatry hospitals located in The Netherlands and Germany [20]. We acknowledge that efforts to truly dissect and understand such national differences with the goal of initiating changes in our clinical systems are very ambitious and obviously time consuming. We are in many ways stuck within our national systems, which in themselves are complex and at times require our maximal attention. Idealism as the motor for pursuit of a European dream does not really represent a foundation for scientists. Therefore, why should we in pragmatic terms aspire to work together within the framework of Europe?

In our internal discussion, we have come up with the following three major arguments, which we wish to share and discuss with our readership:

1. Competition is stiff. A brief look at the scientific output of the USA with its population of 327 million inhabitants is sufficient to understand that no European country by itself can in any way successfully compete. Another country with an increasingly strong output is China. Chinese authored articles submitted to ECAP a decade ago were frequently difficult to read; accordingly, the poor English was one of the reasons leading to rejection of these papers. Nowadays, articles submitted by Chinese researchers are often written in superb English; unfortunately, this high standard is frequently not met by the authors from European countries (excluding the UK). Moreover, to scientifically compete in the rapidly evolving digital and technological revolutions will require large-scaled collaborations. The recent success in elucidation of genetic loci for mental disorders would not have been possible without collaborations initiated many years ago to come up with sample sizes sufficiently large for detection of variants with small effect sizes. Similarly, imaging projects are now geared to investigate thousands of patients. Only strong Euro- pean research teams can have a high impact within these environments. Such teams also need to exert pressure at both the national and European levels to ensure that funding will continue for our field.

2. Our time is too precious to pursue redundant projects at the national levels. Clinical guidelines serve as an excellent example. Some countries are able to come up with national guidelines for the treatment of mental disorders, but only some of them are specific for children and adolescents and even in larger countries not all diagnoses and themes are covered by guidelines. In the UK, the National Institute for Health and Care Excellence (NICE) Guidelines are sponsored by the Department of Health and Social Care. We are not aware of any other country with such a systematic source of funding. Clinician researchers within most European countries with national guidelines need to do the underlying work themselves. Would it not be in the best interest of all parties involved to establish European collaborations to come up with the framework for disorder-specific guidelines especially for children and adolescents? European expert groups could perform the relevant literature searches, meta-analyses and interpretations, which could then be used in each country to adapt the contents of the framework guidelines to the national health care systems, thus overall strongly reducing the work load. Such collaborations would likely stand a better chance of obtaining funding at the European level even for less common or more specific topics; the political pressure would build up across different medical fields.

Other possibilities to make best use of the resources available in Europe include establishing European training programs for specializations. It is difficult to find experts for infrequent conditions even in large European countries; why not join forces to for instance coordinate specialization in transgender issues relevant for our field? Such a European program would generate substantial interest and could ensure a quality control via for instance certifications. Similarly, joint training of early career investigators in for instance the ESCAP Research Academy [16] promotes enthusiasm and initiates networking thus contributing to urgently required recruitment of academic offspring.

Child and adolescent psychiatry is becoming more complex due to the need to accommodate the influx of ever increasing amounts of research results. We need to break this information down to the clinicians. Doing all these works in parallel in different countries even for less common disorders represents a waste of our already limited resources and limits the probability of receiving adequate funding.

3. Novel technologies such as high-throughput screening and artificial intelligence are already beginning to 
influence medicine; there is no doubt that they will also impact child and adolescent psychiatry. Self-learning devices will potentially represent a sine qua non for future therapy. The rapid advances in the field of psychiatric genetics may promote stratified/personalized medicine in our field. We need to integrate these novel technologies into our work and at the same time be vigilant as to side effects at the individual and societal levels. Only a strong European collaboration can reduce the probability that single countries go astray in the complexity of the issues at hand.

In conclusion, we perceive the need to optimally make use of the resources available in Europe. We need individuals to initiate chain reactions within their fields. We need academic and administrative input, we need joint financial resources. We would be more than happy to promote European exchange in every and in any way we as individuals or we as Editors of European Child and Adolescent Psychiatry can do. It is now up to you-contact us.

\section{References}

1. Banzer R, Haring C, Buchheim A, Oehler S, Carli V, Wasserman C, Kaess M, Apter A, Balazs J, Bobes J, Brunner R, Corcoran P, Cosman D, Hoven CW, Kahn JP, Keeley HS, Postuvan V, Podlogar T, Sisask M, Varnik A, Sarchiapone M, Wasserman D (2017) Factors associated with different smoking status in European adolescents: results of the SEYLE study. Eur Child Adolesc Psychiatry 26(11):1319-1329. https://doi.org/10.1007/s0078 7-017-0980-4

2. Bartels M, Hendriks A, Mauri M, Krapohl E, Whipp A, Bolhuis K, Conde LC, Luningham J, Fung Ip H, Hagenbeek F, Roetman P, Gatej R, Lamers A, Nivard M, van Dongen J, Lu Y, Middeldorp C, van Beijsterveldt T, Vermeiren R, Hankemeijer T, Kluft C, Medland S, Lundstrom S, Rose R, Pulkkinen L, Vuoksimaa E, Korhonen T, Martin NG, Lubke G, Finkenauer C, Fanos V, Tiemeier H, Lichtenstein P, Plomin R, Kaprio J, Boomsma DI (2018) Childhood aggression and the co-occurrence of behavioural and emotional problems: results across ages 3-16 years from multiple raters in six cohorts in the EU-ACTION project. Eur Child Adolesc Psychiatry 27:1105-1121. https://doi.org/10.1007/s0078 7-018-1169-1

3. Bolte S, Mahdi S, Coghill D, Gau SS, Granlund M, Holtmann M, Karande S, Levy F, Rohde LA, Segerer W, de Vries PJ, Selb M (2018) Standardised assessment of functioning in ADHD: consensus on the ICF Core Sets for ADHD. Eur Child Adolesc Psychiatry 27:1261-1281. https://doi.org/10.1007/s00787-018-1119-y

4. Freitag CM, Konrad K, Stadler C, De Brito SA, Popma A, Herpertz SC, Herpertz-Dahlmann B, Neumann I, Kieser M, Chiocchetti AG, Schwenck C, Fairchild G (2018) Conduct disorder in adolescent females: current state of research and study design of the FemNAT-CD consortium. Eur Child Adolesc Psychiatry 27:1077-1093. https://doi.org/10.1007/s00787-018-1172-6

5. Fridenson-Hayo S, Berggren S, Lassalle A, Tal S, Pigat D, MeirGoren N, O'Reilly H, Ben-Zur S, Bolte S, Baron-Cohen S, Golan O (2017) 'Emotiplay': a serious game for learning about emotions in children with autism: results of a cross-cultural evaluation. Eur
Child Adolesc Psychiatry 26(8):979-992. https://doi.org/10.1007/ s00787-017-0968-0

6. de Graaf NM, Cohen-Kettenis PT, Carmichael P, de Vries ALC, Dhondt K, Laridaen J, Pauli D, Ball J, Steensma TD (2018) Psychological functioning in adolescents referred to specialist gender identity clinics across Europe: a clinical comparison study between four clinics. Eur Child Adolesc Psychiatry 27:909-919. https://doi.org/10.1007/s00787-017-1098-4

7. Hodes M, Vasquez MM, Anagnostopoulos D, Triantafyllou K, Abdelhady D, Weiss K, Koposov R, Cuhadaroglu F, Hebebrand J, Skokauskas N (2018) Refugees in Europe: national overviews from key countries with a special focus on child and adolescent mental health. Eur Child Adolesc Psychiatry 27:389-399. https ://doi.org/10.1007/s00787-017-1094-8

8. Husky MM, Boyd A, Bitfoi A, Carta MG, Chan-Chee C, Goelitz D, Koc C, Lesinskiene S, Mihova Z, Otten R, Pez O, Shojaei T, Kovess-Masfety V (2018) Self-reported mental health in children ages 6-12 years across eight European countries. Eur Child Adolesc Psychiatry 27:785-795. https://doi.org/10.1007/s0078 7-017-1073-0

9. Iguacel I, Michels N, Fernandez-Alvira JM, Bammann K, De Henauw S, Felso R, Gwozdz W, Hunsberger M, Reisch L, Russo $\mathrm{P}$, Tornaritis M, Thumann BF, Veidebaum T, Bornhorst C, Moreno LA, consortium I (2017) Associations between social vulnerabilities and psychosocial problems in European children. Results from the IDEFICS study. Eur Child Adolesc Psychiatry 26(9):1105-1117. https://doi.org/10.1007/s00787-017-0998-7

10. Mahdi S, Viljoen M, Massuti R, Selb M, Almodayfer O, Karande S, de Vries PJ, Rohde L, Bolte S (2017) An international qualitative study of ability and disability in ADHD using the WHO-ICF framework. Eur Child Adolesc Psychiatry 26(10):1219-1231. https://doi.org/10.1007/s00787-017-0983-1

11. Mahdi S, Ronzano N, Knuppel A, Dias JC, Albdah A, Chien-Ho L, Almodayfer O, Bluschke A, Karande S, Huang HL, Christiansen H, Granlund M, de Vries PJ, Coghill D, Tannock R, Rohde L, Bolte S (2018) An international clinical study of ability and disability in ADHD using the WHO-ICF framework. Eur Child Adolesc Psychiatry 27:1305-1319. https://doi.org/10.1007/s0078 7-018-1124-1

12. McMahon EM, Corcoran P, O'Regan G, Keeley H, Cannon M, Carli V, Wasserman C, Hadlaczky G, Sarchiapone M, Apter A, Balazs J, Balint M, Bobes J, Brunner R, Cozman D, Haring C, Iosue M, Kaess M, Kahn JP, Nemes B, Podlogar T, Postuvan V, Saiz P, Sisask M, Tubiana A, Varnik P, Hoven CW, Wasserman D (2017) Physical activity in European adolescents and associations with anxiety, depression and well-being. Eur Child Adolesc Psychiatry 26(1):111-122. https://doi.org/10.1007/s0078 7-016-0875-9

13. Nature. https://www.nature.com/articles/d41586-019-01060-6. Accessed 24 May 2019

14. Pedersen MU, Thomsen KR, Heradstveit O, Skogen JC, Hesse M, Jones S (2018) Externalizing behavior problems are related to substance use in adolescents across six samples from Nordic countries. Eur Child Adolesc Psychiatry 27:1551-1561. https:// doi.org/10.1007/s00787-018-1148-6

15. Pejovic-Milovancevic M, Klasen H, Anagnostopoulos D (2018) ESCAP for mental health of child and adolescent refugees: facing the challenge together, reducing risk, and promoting healthy development. Eur Child Adolesc Psychiatry 27:253-257. https:// doi.org/10.1007/s00787-017-1064-1

16. Revet A, Hebebrand J, Klauser P (2017) The 2017 ESCAP Research Academy Workshop: bright perspectives for child and adolescent psychiatry. Eur Child Adolesc Psychiatry 26(10):1279_ 1280. https://doi.org/10.1007/s00787-017-1036-5

17. Signorini G, Singh SP, Marsanic VB, Dieleman G, Dodig-Curkovic K, Franic T, Gerritsen SE, Griffin J, Maras A, McNicholas F, 
O’Hara L, Purper-Ouakil D, Paul M, Russet F, Santosh P, Schulze U, Street C, Tremmery S, Tuomainen H, Verhulst F, Warwick J, de Girolamo G, Consortium M (2018) The interface between child/adolescent and adult mental health services: results from a European 28-country survey. Eur Child Adolesc Psychiatry 27:501-511. https://doi.org/10.1007/s00787-018-1112-5

18. Signorini G, Singh SP, Marsanic VB, Dieleman G, Dodig-Curkovic K, Franic T, Gerritsen SE, Griffin J, Maras A, McNicholas F, O'Hara L, Purper-Ouakil D, Paul M, Russet F, Santosh P, Schulze U, Street C, Tremmery S, Tuomainen H, Verhulst F, Warwick J, de Girolamo G, Milestoneconsortium (2018) Correction to: the interface between child/adolescent and adult mental health services: results from a European 28country survey. Eur Child Adolesc Psychiatry 27:1511-1512. https://doi.org/10.1007/s0078 7-018-1132-1
19. Sourander A, Chudal R, Skokauskas N, Al-Ansari AM, Klomek AB, Pornnoppadol C, Kolaitis G, Maezono J, Steinhausen HC, Slobodskaya H, Kaneko H, Regmee J, Li L, Nguyen MH, Grimland M, Osokina O, Ong SH, Praharaj SK, Lesinskiene S, Fossum S, Wiguna T, Makasheva VA, Lehti V (2018) Unmet needs of child and adolescent psychiatrists among Asian and European countries: does the Human Development Index (HDI) count? Eur Child Adolesc Psychiatry 27:5-8. https://doi.org/10.1007/s0078 7-017-1095-7

20. de Veen BTH, Hebebrand J, Staal WG (2018) Improving child and adolescent mental health care provision by scrutiny of national diagnostic practices: a call for increased international knowledge exchange. Eur Child Adolesc Psychiatry 27:1387-1389. https:// doi.org/10.1007/s00787-018-1233-x 